- RAM, REV. ADM. MACKENZIE, 15(5) • SÃO PAULO, SP • SET./OUT. 2014 • ISSN 1518-6776 (impresso) • ISSN 1678-6971 (on-line) • http://dx.doi.org/10.1590/1678-69712014/administracao.v15n5p140-170. Submissão: 28 mar. 2012. Aceitação: 17 jun. 2014. Sistema de avaliação: às cegas dupla (double blind review).

UNIVERSIDADE PRESBITERIANA MACKENZIE. Silvio Popadiuk (Ed.), Josete Florencio dos Santos (Ed. Seção), p. 140-170.

\title{
. \\ CONFORMIDADE DO DISCLOSURE OBRIGATÓRIO DOS ATIVOS INTANGÍVEIS E PRÁTICAS DE GOVERNANÇA CORPORATIVA
}

\section{GEOVANIE DIAS DE MOURA}

Doutor em Ciências Contábeis e Administração pelo Programa de Pós-Graduação em Ciências Contábeis da Universidade Regional de Blumenau (Furb).

Professor da Área de Ciências Sociais Aplicadas da Universidade Comunitária da Região de Chapecó (Unochapecó).

Avenida Senador Atílio Fontana, Servidão Anjo da Guarda, 591-E, Efapi, Chapecó - SC - Brasil - CEP 89809-900

E-mail: geomoura@terra.com.br

\section{PATRÍCIA SIQUEIRA VARELA}

Doutora em Controladoria e Contabilidade pela Faculdade de Economia, Administração e Contabilidade da Universidade de São Paulo (FEA-USP).

Avenida Professor Luciano Gualberto, 908, Prédio 3, Cidade Universitária, São Paulo - SP - Brasil - CEP 05508-900

E-mail: psvarela@usp.br

\section{ILSE MARIA BEUREN}

Doutora em Controladoria e Contabilidade pela Faculdade de Economia, Administração e Contabilidade da Universidade de São Paulo (FEA-USP).

Professora Titular do Departamento de Ciências Contábeis da Universidade Federal do Paraná (UFPR). Avenida Prefeito Lothário Meissner, 632, Campus III, Jardim Botânico, Curitiba - PR - Brasil - CEP 80210-170

E-mail: ilse.beuren@gmail.com

Este artigo pode ser copiado, distribuído, exibido, transmitido ou adaptado desde que citados, de forma clara e explícita, o nome da revista, a edição, o ano, e as páginas nas quais o artigo foi publicado originalmente, mas sem sugerir que a RAM endosse a reutilização do artigo. Esse termo de licenciamento deve ser explicitado para os casos de reutilização ou distribuição para terceiros. Não é permitido o uso para fins comerciais. 


\section{RESUMO}

O estudo objetiva verificar se empresas com maiores proporções de ativos intangíveis no ativo total e melhores práticas de governança corporativa apresentam maior conformidade com o disclosure obrigatório de tais ativos. Pesquisa descritiva, com abordagem quantitativa, foi conduzida por meio de análise documental em uma amostra de 260 empresas de seis setores econômicos da BM\&FBovespa. Para cada empresa calculou-se o percentual dos ativos intangíveis em relação ao ativo total. O índice de governança corporativa foi pautado no estudo de Leal e Carvalhal-da-Silva (2007) e o índice de conformidade das informações divulgadas sobre ativos intangíveis foi baseado no CPC 04. Os resultados revelaram representatividade dos intangíveis, que de maneira geral equivalem a $\mathrm{I} 7 \%$ do ativo total, mas algumas empresas, principalmente aquelas de setores com maiores proporções, possuem índices mais expressivos. $\mathrm{Na}$ qualidade das práticas de governança encontrou-se um índice médio de $55 \%$ e no nível de evidenciação de informações sobre intangíveis, um índice médio de $75 \%$. A correlação de Pearson mostrou-se positiva e significativa estatisticamente, corroborando o descrito no objetivo do estudo. Assim, conclui-se que entre empresas de diferentes setores da BM\&FBovespa, aquelas com maiores proporções de ativos intangíveis no ativo total e melhores práticas de governança corporativa apresentam maior conformidade com o disclosure obrigatório de tais ativos.

\section{PALAVRAS-CHAVE}

Disclosure obrigatório. Ativos intangíveis. Ativo total. Melhores práticas. Governança corporativa. 


\section{INTRODUÇÃ}

O cenário econômico mundial é caracterizado por uma intensa concorrência empresarial, que, combinada com o aparecimento de novas tecnologias e o aumento das exigências dos clientes, tem resultado em ambientes de mudanças rápidas e constantes. Nesse contexto, os ativos tangíveis que, segundo Rolim (2009, p. 20), já foram tratados em outro momento como "símbolos de prosperidade e sucesso empresarial”, estão perdendo espaço para os ativos intangíveis, como marcas, patentes, softwares de computador, direitos autorais e carteiras de clientes.

Nesse cenário cada vez mais desenvolvido, as empresas não podem limitar-se apenas a fatores tradicionais, tais como capital e trabalho, pois precisam apresentar diferenciais para se manter competitivas e responder mais rapidamente a essas mudanças (Johanson, Martensson, \& Skoog, 200I; Tavares, 2010). Os ativos intangíveis passaram a ser reconhecidos como fontes de vantagem competitiva, além de contribuírem para o aumento do valor da empresa (Stewart, I998; Sveiby, I998; Hendriksen \& Van Breda, I999; Lev, 200I; Kayo, Teh, \& Basso, 2006; Sriram, 2008). Porém, para que isso ocorra, é necessário que as informações sobre ativos intangíveis sejam evidenciadas ao mercado, a fim de sinalizarem aos investidores que a companhia realmente sabe quanto valem os seus intangíveis (Antunes, Leite, \& Guerra, 2009).

Considerando o aumento da importância dos ativos intangíveis na economia mundial e visando à maximização do poder informativo das demonstrações financeiras, nos Estados Unidos, em 200I, o Financial Accounting Standards Board (Fasb) redefiniu o tratamento dado aos ativos intangíveis para o mercado norte-americano com a emissão do Pronunciamento n. I42 - Ágio e Outros Ativos Intangíveis. Em 2004, o International Accounting Standards Board (Iasb), órgão internacional que publica e atualiza normas internacionais de contabilidade, alterou o texto da norma International Accounting Standard (IAS) n. 38, prescrevendo novos critérios para reconhecimento, mensuração e divulgação. No Brasil, em 2008, visando à convergência das normas brasileiras aos padrões internacionais, ocorreu a aprovação do CPC ०4 - Ativo Intangível que tem como base o IAS 38 .

Essas mudanças contribuem para a melhoria da evidenciação de informações nas demonstrações financeiras, possibilitando que os seus usuários sejam capazes de compreender melhor os investimentos realizados em ativos intangíveis e o desempenho futuro da empresa. De acordo com Hendriksen e Van Breda (I999), um dos objetivos da evidenciação de informações é transmitir confiança 
para a tomada de decisões. Com base nessa ideia, acredita-se que a evidenciação de informações referentes aos ativos intangíveis torna-se essencial.

A divulgação também é uma das características da governança corporativa nas empresas. Segundo o código das melhores práticas de governança corporativa do Instituto Brasileiro de Governança Corporativa (IBGC) (2009, p. I9), “[...] a adequada transparência resulta em um clima de confiança, tanto internamente quanto nas relações da empresa com terceiros".

O código do IBGC (2009, p. I9) destaca que as informações evidenciadas não devem "[...] restringir-se apenas ao desempenho econômico financeiro", mas deve contemplar "[...] também os demais fatores (inclusive intangíveis)". Para Andrade e Rossetti (2007), as práticas de governança corporativa podem contribuir para o aumento da evidenciação que resulta em maior confiança dos investidores. De acordo com Kent e Stewart (2008), a governança corporativa pode contribuir para um correto cumprimento das regulamentações contábeis, as quais envolvem o reconhecimento e mensuração dos intangíveis, e ainda, no monitoramento dos valores investidos na aquisição de novos intangíveis.

Em relação aos investimentos em ativos intangíveis, Himmelberg, Hubbard e Palia (I999) relatam que as empresas que possuem maiores valores de intangíveis têm maior necessidade de adotar melhores práticas de governança corporativa e de evidenciar mais informações com o intuito de sinalizar aos investidores que não farão mau uso dos seus intangíveis no futuro. O mesmo pensamento é compartilhado por Klapper e Love (2004), Silveira (2002, 2004).

As práticas de governança corporativa, conforme descrevem Kent e Stewart (2008), estão contribuindo, em diversos países, para a adoção correta das novas regulamentações contábeis sobre ativos intangíveis e, também, para elevar os padrões de qualidade das informações e assegurar adequada comunicação com investidores sobre a implantação e desempenho desses ativos.

Com base no exposto, elaborou-se a seguinte questão de pesquisa: Empresas de diferentes setores da BM\&FBovespa, com maiores proporções de ativos intangíveis no ativo total e melhores práticas de governança corporativa, apresentam maior conformidade com o disclosure obrigatório de tais ativos? Assim, o estudo objetiva verificar se empresas com maiores proporções de ativos intangíveis no ativo total e melhores práticas de governança corporativa apresentam maior conformidade com o disclosure obrigatório de tais ativos.

No Brasil, há pesquisas sobre a evidenciação voluntária de informações relativas aos ativos intangíveis, como os estudos de Santos, Gallon e Ensslin (2007), Rêgo, Araújo Neto, Barbosa e Cavalcante (2008), Macagnan (2009), Matos, Ensslin, Reina e Reina (2009), Schnorrenberger, Sousa e Reina (2009). Há também estudos que investigaram aspectos estipulados pela Lei n. II.638/07, como é o 
caso de Pereira, Lemes, Alves e Ferreira (2007), Antunes, Silva e Saiki (2009), Galo (2009), Jordão e Colauto (2009), Cunha, Souza, Santana, Magalhães, Pelegrini e Malaquias (20I0). No entanto, ainda há necessidade de estudos que verifiquem se as empresas brasileiras estão evidenciando todas as informações determinadas pelo CPC o4, que envolvem critérios de reconhecimento, mensuração e divulgação dos intangíveis.

A representatividade dos intangíveis no patrimônio das empresas é um tema abordado nos estudos de Kayo, Teh e Basso (2006), Perez e Famá (2006), Nascimento, Oliveira, Marques e Cunha (20I2), Decker, Ensslin, Reina e Reina (2013) e Moura, Mecking e Scarpin (2013). No entanto, ainda há necessidade de estudos que verifiquem a relação positiva entre proporção de intangíveis em uma empresa e melhores práticas de governança corporativa. Outra justificativa para o estudo refere-se à falta de trabalhos empíricos que testem a hipótese estabelecida por Kent e Stewart (2008) e Oliveira, Rodrigues e Craig (2010), de que as práticas de governança corporativa contribuem para a melhoria da evidenciação de informações sobre intangíveis.

\section{Ativos INTANGíveIS}

O termo ativo intangível tem sido utilizado como sinônimo de recursos intangíveis, ativos intelectuais, ativos invisíveis, capital intelectual e goodwill, conforme pode ser verificado nos estudos de Martins (I972), Crawford (I994), Brooking (I996), Edvinsson e Malone (1998), Sveiby (I998), Stewart (1998), Caddy (2002), Hitt, Ireland e Hoskisson (2003), Antunes (2004). Neste estudo, adota-se a denominação ativos intangíveis por entender, assim como nos estudos de Kayo (2002), Kaufmann e Schneider (2004), Schnorrenberger (2005) e Vargas (2007), que esse termo caracteriza melhor a abordagem.

Para compreender as definições de ativo intangível, é necessária uma análise inicial de alguns conceitos relacionados ao ativo. Segundo Martins (I972, p. 30), ativo "é o futuro resultado econômico que se espera obter de um agente". $\mathrm{O}$ autor esclarece que o agente pode ser um computador, que presta diversos serviços, como cálculo e armazenagem de dados; um caminhão, que proporciona o resultado transporte; patentes, licenças ou direitos autorais, que proporcionarão resultados. No entanto, a ênfase está no futuro resultado econômico esperado e não no agente. Martins (I972, p. 29) exemplifica o caso de um computador, que ao ser registrado no balanço será denominado "computador, que é o nome do agente, porém o que realmente está se definindo como ativo é o seu potencial de serviços futuros". 
O Pronunciamento Conceitual Básico (2008, p. I6), do Comitê de Pronunciamentos Contábeis, define ativo como "um recurso controlado pela entidade como resultado de eventos passados e do qual se espera que resultem benefícios econômicos para a entidade". Dessa forma, podem ser considerados como ativo todos os recursos com ou sem natureza física, que sejam controlados pela empresa e capazes de proporcionar a ela obtenção de benefícios econômicos (fluxos de caixa).

Ter controle sobre um intangível, para Crisóstomo e Freire (2005), significa que a organização tem o direito de utilizá-lo em suas atividades para obtenção de benefícios. Os autores complementam que o controle resulta de algum evento passado, como a aquisição ou criação pela própria empresa. Para Hendriksen e Van Breda (I999), o controle está associado à necessidade de um poder legal respeitável capaz de garantir os recebimentos dos benefícios futuros. Os autores esclarecem que uma maneira de identificar o controlador é analisar para quem o intangível proporcionará os benefícios futuros. Ritta, Ensslin e Ronchi (20I0) mencionam que a entidade controladora deve ser a única a obter os benefícios desse ativo.

A necessidade de se ter associado aos ativos intangíveis a capacidade de geração de benefício futuro também é compartilhada por Hendriksen e Van Breda (I999), Lev (200I), Martins (2002), Schmidt e Santos (2002), Iudícibus (2004), Milone (2004), Silveira, Leal, Barros e Carvalhal-da-Silva (2009). Ritta, Ensslin e Ronchi (20I0) descrevem que benefício econômico futuro é a capacidade de o intangível contribuir com a geração de receitas, seja isoladamente ou em conjunto com outros ativos.

Os ativos tangíveis, para Hitt, Ireland e Hoskisson (2003, p. I05), são aqueles que podem ser vistos e quantificados facilmente, tais como equipamentos de produção, veículos e móveis. Porém, à medida que a aquisição desses ativos tangíveis torna-se acessível e estes podem ser obtidos por todo tipo de empresa, o que diferencia uma das outras, segundo Kayo (2002), passa a ser os ativos intangíveis. Segundo o autor, pode ocorrer a aquisição de terrenos ou edifícios semelhantes ou, então, a compra das mesmas máquinas e equipamentos, mas a habilidade para gerar riquezas das pessoas, as marcas, as patentes, entre outros ativos denominados intangíveis, são únicos para cada empresa.

Nesse sentido, visando a diferenciação dos concorrentes, o investimento em ativos intangíveis é um fenômeno que se intensifica nas empresas de todos os setores e atividades, conforme relatam Goldfinger (I997) e Lev (200I). Sendo assim, torna-se relevante que as empresas brasileiras cumpram as determinações estabelecidas pelo CPC 04 sobre intangíveis, principalmente em relação às exigências de divulgação de informações, que possibilitam maior entendimento sobre os intangíveis. 


\section{EVIDENCIAÇÃO DE ATIVOS INTANGÍVEIS}

A evidenciação ou disclosure torna-se importante, de acordo com Iudícibus (2004, p. 8I), "ao garantir informações diferenciadas para os vários tipos de usuários". O autor menciona que o disclosure pode ser uma alternativa para a contabilidade diminuir as falhas de informações, principalmente no que se refere à demanda de informação externa por parte de acionistas e investidores. Essa mesma opinião é compartilhada por Backes, Ott e Wiethaeuper (2005). A evidenciação de informações é uma forma interessante que as empresas utilizam para diminuir a assimetria de informações e os conflitos de agência entre administradores e os diversos grupos de stakeholders (Healy \& Palepu, 200I).

Hendriksen e Van Breda (I999, p. I62) mencionam que "[...] há assimetria informacional quando uma das partes da transação possui mais informação do que outra". Segundo Healy e Palepu (200I), a assimetria da informação ocorre quando algum agente em um modelo de informação financeira ou econômica possui mais informação sobre certa empresa ou ativo do que outro agente. Os conflitos de agência surgem nas empresas atuais, segundo Lopes e Martins (2007), principalmente em virtude da separação da propriedade e da gestão, que resulta em conflitos de interesse, tratados pela literatura sobre teoria da agência.

O disclosure de ativos intangíveis, de acordo com Sveiby (I998), é relevante e está associado a necessidades internas e externas que as empresas têm. Em relação à necessidade interna, o autor menciona que a evidenciação ocorre para que a gerência possa conhecer, monitorar e tomar medidas corretivas sobre seus intangíveis. A necessidade de evidenciação externa ocorre para uma maior transparência perante os clientes, credores, fornecedores, governo, acionistas e demais stakeholders.

Os critérios específicos sobre a evidenciação obrigatória de ativos intangíveis, no Brasil, são determinados pelo CPC 04, que determina que os ativos intangíveis devem ser separados por classes, por exemplo: marcas, títulos de periódicos, softwares, licenças e franquias, direitos autorais, receitas, fórmulas, projetos e intangíveis em desenvolvimento. Devem ser divulgadas informações sobre o valor de custo e valor líquido acumulado dos intangíveis no início do período, os valores do período, bem como os valores acumulados no final do período, juntamente com os respectivos valores, taxas e métodos de amortização.

O CPC 04 também determina que as empresas divulguem se a vida útil do intangível é definida ou indefinida, justificando os motivos que fundamentam a avaliação e os fatores mais importantes que levaram à respectiva definição, além 
dos prazos de vida útil ou as taxas de amortização utilizadas. Informações sobre adições, baixas e transferências (indicando separadamente as que foram geradas por desenvolvimento interno e as adquiridas), ativos classificados como mantidos para venda ou outras baixas, bem como os adquiridos por meio de combinação de negócios também precisam ser divulgadas.

A empresa deve divulgar ainda informações sobre ativos intangíveis que perderam o seu valor de acordo com o Pronunciamento Técnico CPC oI - Redução ao Valor Recuperável de Ativos. O CPC também prevê informações para reavaliação, porém, no Brasil, tal prática não é permitida devido às disposições contidas na Lei n. Ir.638/07, que alterou a Lei n. 6.404/76, com vigência a partir de I $^{\circ}$. de janeiro de 2008 .

Outra evidenciação obrigatória pela entidade, de acordo com o CPC ०4, refere-se ao total gasto com pesquisa e desenvolvimento reconhecido como despesa no período, como custos com empregados, taxas de registro de direitos legais, amortização de patentes etc. No entanto, até a aprovação do CPC 04, a evidenciação voluntária dos ativos intangíveis é que vinha exercendo o importante papel de possibilitar mais informações aos stakeholders. Nesta pesquisa, serão avaliadas apenas as evidenciações obrigatórias constantes no CPC o4, em virtude de já existirem diversos estudos recentes sobre a evidenciação voluntária e sobre aspectos estipulados pela Lei n. II.638/07.

\section{GOVERNANÇA CORPORATIVA E EVIDENCIAÇÃO DE ATIVOS INTANGÍVEIS}

O interesse pela governança corporativa, segundo Bebchuk e Weisbach (20IO), tem crescido rapidamente com o passar dos anos, tanto no meio acadêmico quanto no empresarial, juntamente com o reconhecimento de sua importância. No meio acadêmico, esse interesse, de acordo com Bebchuk e Weisbach (20I0), tem sido verdadeiramente interdisciplinar, pois o tema é estudado por pesquisadores da economia, finanças, direito, administração e contabilidade.

Esse aumento de interesse pelo tema ocorreu, principalmente, a partir do ano de 2002, como consequência da necessidade de aprimoramento da governança corporativa. De certa forma, foi resposta para diversos registros de expropriação da riqueza em virtude de informações distorcidas ou não prestadas por grandes empresas como Enron, Worldcom, Xerox, Banco Nacional, Parmalat (Silveira, 2002; Lanzana, 2004; Silveira, 2004; Beekes \& Brown, 2006; Khanchel, 2007; Nascimento \& Reginato, 2008; Bebchuk \& Weisbach, 20I0; Prado, 2010). 
A governança corporativa é descrita por Andrade e Rossetti (2007, p. 24) como sendo "meios utilizados pelas corporações para estabelecer processos que ajustem os interesses em conflito entre os acionistas das empresas e seus dirigentes de alto nível". Segundo os autores, essas ações, além de deixarem a empresa menos exposta aos riscos externos e de gestão, tornam o negócio mais seguro, o que aumenta a confiança dos investidores. A adoção de práticas de governança corporativa fortalece o mercado de capitais ao contribuir para o acesso a informações de qualidade sobre a empresa. Essas práticas são estabelecidas por meio de um sistema eficaz que garante uma boa administração, a partir da formalização de conceitos adequados e úteis (Andrade \& Rossetti, 2007).

Silveira (2004) menciona que é necessário proporcionar maior proteção ao investidor para evitar os problemas ocorridos nas empresas citadas. O autor entende que uma alternativa seria o aumento de evidenciação das decisões tomadas pelos controladores e, para isso, a governança corporativa desempenha papel fundamental. Esse pensamento é compartilhado por Carvalho (2002) e Aksu e Kosedag (2006), ao descreverem que uma das formas de minimizar a assimetria de informação e os problemas de agência é por meio da adoção de um sistema de governança corporativa que contribua para maior transparência nas decisões por meio de um aumento na evidenciação.

Portanto, as práticas de governança corporativa podem contribuir para a melhoria da divulgação de informações sobre os ativos intangíveis nas empresas, conforme mencionam Kent e Stewart (2008). Keenan e Aggestam (200I) aduzem que a governança corporativa também pode contribuir de maneira efetiva no momento de realizar novas aquisições em ativos intangíveis e na gestão para o correto cumprimento das regulamentações contábeis que envolvem o reconhecimento e mensuração desses intangíveis.

Para demonstrar a importância da governança corporativa no aumento da evidenciação de informações sobre ativos intangíveis, Himmelberg, Hubbard e Palia (I999) citam como exemplo duas empresas com características gerais semelhantes, porém, uma delas operando com maior fração de ativos intangíveis. No exemplo, em virtude de os intangíveis serem ativos de controle mais difícil, a empresa com maior proporção desses ativos teria maior facilidade de expropriar os investidores.

As empresas que possuem maiores frações de ativos intangíveis, de acordo com Himmelberg, Hubbard e Palia (I999), teriam maior necessidade de adotarem melhores práticas de governança corporativa do que as empresas com maiores frações de ativos tangíveis. O mesmo pensamento é compartilhado por Klapper e Love (2004) e Silveira (2002, 2004) ao descreverem que em virtude de as empresas possuírem maior proporção de intangíveis, teriam 
maior necessidade de sinalizar aos investidores que não farão mau uso dos seus intangíveis no futuro.

Empresas que dispõem de boas práticas de governança corporativa podem reduzir as preocupações que têm sido levantadas em virtude de ativos intangíveis não estarem sendo reconhecidos de maneira correta, pois transmitem maior confiabilidade ao mercado (Oliveira, Rodrigues, \& Craig, 20Io). Em decorrência da convergência para as normas internacionais de contabilidade sobre intangíveis que ocorre em diversos países, segundo Kent e Stewart (2008), as práticas de governança podem contribuir para elevar os padrões de qualidade das informações sobre esses ativos e assegurar a comunicação com investidores sobre a implantação e o desempenho dos intangíveis.

\section{METODOLOGIA DA PESQUISA}

Pesquisa descritiva, com abordagem quantitativa, foi realizada por meio de pesquisa documental. A pesquisa caracteriza-se como descritiva, pois, de acordo com Martins e Theóphilo (2007, p. 28), "tem como objetivo a descrição das características de determinada população ou fenômeno, bem como o estabelecimento de relações entre variáveis e fatos". Segundo Vergara (2000, p. 47), a pesquisa descritiva "expõe características de determinada população ou de determinado fenômeno. Pode também estabelecer correlações".

A caracterização como pesquisa documental, conforme Marconi e Lakatos (2002, p. 62), é quando "a fonte de coleta de dados está restrita a documentos, escritos ou não, constituindo o que se denomina de fontes primárias". Neste estudo, os dados foram extraídos do Balanço Patrimonial, Notas Explicativas, Relatórios da Administração e Informações Anuais (IANs) (documento que contém informações corporativas, como número de membros do conselho de administração), disponibilizados no site da BM\&FBovespa referente ao ano base de 2009. Também foram realizadas consultas nos sites das empresas da amostra e da Comissão de Valores Mobiliários (CVM).

Em relação à abordagem quantitativa, Richardson (i999, p. 29) destaca que esse tipo de pesquisa

[...] caracteriza-se pelo emprego da quantificação tanto nas modalidades de coleta de informações, quanto no tratamento dessas através de técnicas estatísticas, desde as mais simples às mais complexas, como coeficiente de correlação, análise de regressão etc. 
Para atingir o objetivo do estudo, foi aplicado como método estatístico a análise de correlação.

A população da pesquisa compreendeu todas as empresas listadas em todos os setores da BM\&FBovespa que constavam na lista, consultada em 3I de março de 20II, disponibilizada pela instituição, com exceção das empresas do setor financeiro e outros, que foram excluídas em virtude das peculiaridades do setor, totalizando, assim, 392 empresas.

Para definição da amostra, inicialmente, por meio dos balanços patrimoniais disponíveis no site da BM\&FBovespa, foram identificadas as empresas que possuíam ativos intangíveis no ano de 2009 (366 empresas identificadas). Em seguida, foi verificado qual era o percentual dos ativos intangíveis em relação ao ativo total, em cada uma das 366 companhias que possuíam ativos intangíveis. Esse cálculo permitiu identificar a média de representatividade dos ativos intangíveis por setor de atividade da BM\&FBovespa, conforme demonstrado na Tabela I:

\section{TABELA I}

PERCENTUAL MÉDIO DOS INTANGÍVEIS EM RELAÇÃO AO ATIVO TOTAL NAS EMPRESAS DE NOVE SETORES ECONÔMICOS DA BM\&FBOVESPA NO ANO DE 2009

\begin{tabular}{|clcc}
\hline RANK & SETOR & No. DE EMPRESAS & $\begin{array}{c}\text { \% DE PROPORÇÃO MÉDIA } \\
\text { EM RELAÇÃO AO ATIVO TOTAL }\end{array}$ \\
\hline 1 & Utilidade pública & 65 & $29 \%$ \\
\hline 2 & Construção e transporte & 67 & $23 \%$ \\
\hline 3 & Tecnologia da informação & 6 & $23 \%$ \\
\hline 4 & Telecomunicações & 31 & $18 \%$ \\
\hline 5 & Consumo não cíclico & 33 & $14 \%$ \\
\hline 6 & Petróleo, gás e biocombustíveis & 42 & $14 \%$ \\
\hline 7 & Consumo cíclico & 51 & $10 \%$ \\
\hline 8 & Bens industriais & 31 & $\mathbf{7 1} \%$ \\
\hline 9 & Materiais básicos & 40 & $\mathbf{1 6 \%}$ \\
\hline TOTAL DE EMPRESAS & $\mathbf{3 6 6}$ & \\
\hline
\end{tabular}

Fonte: Elaborada pelos autores. 
Entre os nove setores apresentados na Tabela I, a amostra da pesquisa, considerada intencional e não probabilística, foi redefinida para as 260 empresas dos três setores com maior representatividade de intangíveis no ativo total - utilidade pública, construção e transporte e tecnologia da informação - e dos três setores com menor representatividade - consumo cíclico, bens industriais e materiais básicos.

Após obter a amostra final (260 empresas), calculou-se o índice de governança corporativa, elaborado de acordo com o estudo de Leal e Carvalhal-da-Silva (2007). O índice apresenta quatro dimensões para avaliar as práticas de governança corporativa: evidenciação; composição e funcionamento do conselho de administração; ética e conflito de interesses; e direito dos acionistas. O índice foi elaborado por Leal e Carvalhal-da-Silva (2007) a partir de recomendações constantes do código de melhores práticas de governança do IBGC, das orientações da Organização para a Cooperação e Desenvolvimento Econômico (OCDE) e da cartilha de boas práticas da CVM.

Essa forma de avaliação das práticas de governança, por meio de índices semelhantes, já foi realizada por outros pesquisadores, entre eles: Black (200I), Klapper e Love (2004), Silveira (2002, 2004), Gompers, Ishii e Metrick (2003), Black, Jang e Kim (2006), Lopes e Walker (2008), Rezende, Facure e Dalmácio (2009), Silveira, Leal, Carvalhal-da-Silva e Barros (20I0), principalmente como tentativa de avaliar o impacto sobre o desempenho das empresas.

A vantagem da utilização de índices para avaliar a qualidade das práticas de governança corporativa é citada em estudos como os de Leal e Carvalhal-da-Silva (2007), Silveira et al. (2010), Lopes e Walker (2008). No caso do índice utilizado nesta pesquisa, Leal e Carvalhal-da-Silva (2007) atribuem a ele a vantagem da possibilidade de os dados serem coletados manualmente por meio de fontes públicas de informação (não exigindo a aplicação de questionários, o que pode resultar numa baixa taxa de respondentes). Além disso, o índice é transparente, de fácil replicação, uma vez que não requer julgamentos subjetivos, e é de fácil interpretação.

O Quadro I apresenta as referidas dimensões de governança corporativa e as 24 perguntas que formaram o índice. As respostas foram obtidas por meio de consultas ao site das empresas, IANs, Notas Explicativas, Relatórios da Administração e site da CVM. 


\section{OUADRO I}

\section{DIMENSÖES DE GOVERNANÇA CORPORATIVA}

\begin{tabular}{|c|c|c|}
\hline $\begin{array}{l}\text { DIMENSÕES DE } \\
\text { GOVERNANÇA } \\
\text { CORPORATIVA }\end{array}$ & & PERGUNTAS PARA CONSTRUÇÃO DO ÍNDICE DE GOVERNANÇA CORPORATIVA \\
\hline \multirow{6}{*}{ Evidenciação } & 1 & $\begin{array}{l}\text { O Relatório Anual da companhia, site ou outro meio de divulgação } \\
\text { pública disponibiliza informações sobre potenciais conflitos de } \\
\text { interesse, tais como operações com partes relacionadas? }\end{array}$ \\
\hline & 2 & $\begin{array}{l}\text { A companhia especifica nos relatórios anuais ou outros meios } \\
\text { sanções contra a Administração, no caso de violações de suas } \\
\text { práticas de governança? }\end{array}$ \\
\hline & 3 & $\begin{array}{l}\text { A empresa divulgou suas demonstrações financeiras legalmente } \\
\text { obrigatórias no prazo previsto? }\end{array}$ \\
\hline & 4 & A companhia utiliza normas internacionais de contabilidade? \\
\hline & 5 & $\begin{array}{l}\text { A companhia utiliza uma das principais empresas de auditoria } \\
\text { mundial? (PWC, Coopers \& Lybrand, KPMG, Ernst \& Young, Touche, } \\
\text { Deloitte \& Touche Tohmatsu) }\end{array}$ \\
\hline & 6 & $\begin{array}{l}\text { A companhia divulga em seus relatórios anuais, site ou outro meio } \\
\text { informações sobre remuneração para o presidente ou membros da } \\
\text { diretoria e do conselho de administração? }\end{array}$ \\
\hline \multirow{6}{*}{$\begin{array}{l}\text { Composição e } \\
\text { funcionamento } \\
\text { do conselho de } \\
\text { administração }\end{array}$} & 7 & $\begin{array}{l}\text { Os cargos de presidente da companhia e presidente do conselho de } \\
\text { administração são ocupados por pessoas diferentes? }\end{array}$ \\
\hline & 8 & $\begin{array}{l}\text { A empresa possui comitês de acompanhamento, como o comitê de } \\
\text { auditoria, por exemplo? }\end{array}$ \\
\hline & 9 & $\begin{array}{l}\text { O conselho é composto por uma maioria de conselheiros } \\
\text { independentes? }\end{array}$ \\
\hline & 10 & $\begin{array}{l}\text { A empresa possui um conselho de administração com } 5 \text { a } 11 \\
\text { membros, conforme recomendado pelo código das melhores } \\
\text { práticas do IBGC? }\end{array}$ \\
\hline & 11 & $\begin{array}{l}\text { Os membros do conselho possuem mandato unificado não superior } \\
\text { a dois anos? }\end{array}$ \\
\hline & 12 & ste um conselho fiscal permanente? \\
\hline
\end{tabular}




\section{QUADRO I (CONCLUSÃO)}

\section{DIMENSÖES DE GOVERNANÇA CORPORATIVA}

\begin{tabular}{|c|c|c|}
\hline $\begin{array}{l}\text { DIMENSÕES DE } \\
\text { GOVERNANÇA } \\
\text { CORPORATIVA }\end{array}$ & & PERGUNTAS PARA CONSTRUÇÃO DO ÍNDICE DE GOVERNANÇA CORPORATIVA \\
\hline \multirow{6}{*}{$\begin{array}{l}\text { Ética e conflitos } \\
\text { de interesse }\end{array}$} & 13 & $\begin{array}{l}\text { A empresa está livre de quaisquer inquéritos submetidos à CVM a } \\
\text { respeito de más práticas de governança? }\end{array}$ \\
\hline & 14 & $\begin{array}{l}\text { A empresa está livre de condenações perante a CVM e/ou multas } \\
\text { por irregularidades governamentais nos últimos cinco anos? }\end{array}$ \\
\hline & 15 & $\begin{array}{l}\text { No caso de más práticas de governança corporativa, a empresa se } \\
\text { submete a câmaras de arbitragem em vez de processos judiciais? }\end{array}$ \\
\hline & 16 & $\begin{array}{l}\text { O acionista controlador, considerando os acordos de acionistas, } \\
\text { possui menos de } 50 \% \text { do capital votante? }\end{array}$ \\
\hline & 17 & $\begin{array}{l}\text { O percentual de ações sem direito a voto é inferior a } 20 \% \text { do capital } \\
\text { total da empresa? }\end{array}$ \\
\hline & 18 & $\begin{array}{l}\text { O total de ações detidas na empresa pelo controlador dividido pelo } \\
\text { percentual que possui apenas das ações com direito a voto é maior } \\
\text { que } 1 \text { ? }\end{array}$ \\
\hline \multirow{6}{*}{$\begin{array}{l}\text { Direitos dos } \\
\text { acionistas }\end{array}$} & 19 & $\begin{array}{l}\text { A empresa tem algum tipo de tratamento ou faz algum tipo de } \\
\text { verificação das ações, para facilitar o processo de votação a todos os } \\
\text { acionistas além do que é legalmente exigido? }\end{array}$ \\
\hline & 20 & $\begin{array}{l}\text { A companhia concede direitos adicionais de voto além do que é } \\
\text { legalmente exigido? }\end{array}$ \\
\hline & 21 & $\begin{array}{l}\text { A empresa concede tag along aos detentores de ações } \\
\text { preferenciais? }\end{array}$ \\
\hline & 22 & $\begin{array}{l}\text { Existem estruturas piramidais de acionistas que reduzem a } \\
\text { concentração de controle? }\end{array}$ \\
\hline & 23 & A empresa possui Acordo de Acionistas? \\
\hline & 24 & $\begin{array}{l}\text { As ações disponíveis para negociação são em número maior ou igual } \\
\text { ao que é exigido pela BM\&FBovespa ( } 25 \%) \text { ? }\end{array}$ \\
\hline
\end{tabular}

Fonte: Adaptado de Leal e Carvalhal-da-Silva (2007). 
Na formação do índice de governança corporativa, as respostas foram binárias (o e I), sendo I para as informações que representaram boas práticas de governança corporativa e o para aquelas que não. Todas as questões também tinham o mesmo peso e ao final cada empresa obteve uma pontuação que variou de $\circ$ (pior) a 24 (melhor).

Na sequência, foi calculado o índice de conformidade das informações divulgadas sobre ativos intangíveis nas Notas Explicativas e Relatórios da Administração, buscando observar se as informações foram apresentadas conforme as determinações do CPC 04. Para calcular o índice, foi elaborado o construto a partir do CPC 04. O Quadro 2 apresenta as informações que devem ser divulgadas conforme orientação do pronunciamento técnico.

\section{QUADRO 2}

INFORMAÇÕES OBRIGATÓRIAS A SEREM

DIVULGADAS SOBRE ATIVO INTANGÍVEL

\begin{tabular}{|c|c|c|}
\hline $\begin{array}{l}\text { DIMENSÃO } \\
\text { DE ATIVOS } \\
\text { INTANGÍVEIS }\end{array}$ & & PERGUNTAS PARA CONSTRUÇÃO DO ÍNDICE DE ATIVOS INTANGIVEIS \\
\hline \multirow{9}{*}{ Vida útil/valor } & 1 & Divulgou informações sobre intangíveis separados em classes? \\
\hline & 2 & Divulgou se os intangíveis são de vida útil definida ou indefinida? \\
\hline & 3 & $\begin{array}{l}\text { Divulgou os motivos que fundamentam e os fatores mais importantes } \\
\text { que levaram à definição da vida útil definida ou indefinida do intangível? }\end{array}$ \\
\hline & 4 & $\begin{array}{l}\text { Divulgou informações sobre os prazos de vida útil ou as taxas de } \\
\text { amortização utilizadas? }\end{array}$ \\
\hline & 5 & $\begin{array}{l}\text { Divulgou o valor contábil bruto da classe de intangível no início do } \\
\text { período? }\end{array}$ \\
\hline & 6 & $\begin{array}{l}\text { Divulgou o valor contábil bruto da classe de intangível no final do } \\
\text { período? }\end{array}$ \\
\hline & 7 & Divulgou o valor contábil de ativos intangíveis cuja titularidade é restrita? \\
\hline & 8 & $\begin{array}{l}\text { Divulgou o valor contábil de ativos intangíveis oferecidos como garantia } \\
\text { de obrigações? }\end{array}$ \\
\hline & 9 & $\begin{array}{l}\text { Divulgou o valor dos compromissos contratuais advindos da aquisição de } \\
\text { ativos intangíveis? }\end{array}$ \\
\hline
\end{tabular}

(continua) 
QUADRO 2 (CONTINUAÇÃO)

INFORMAÇÖES OBRIGATÓRIAS A SEREM

DIVULGADAS SOBRE ATIVO INTANGÍVEL

\begin{tabular}{|c|c|c|}
\hline $\begin{array}{l}\text { DIMENSÃO } \\
\text { DE ATIVOS } \\
\text { INTANGIVEIS }\end{array}$ & & PERGUNTAS PARA CONSTRUÇÃO DO ÍNDICE DE ATIVOS INTANGIVEIS \\
\hline \multirow{5}{*}{ Amortização } & 10 & Divulgou o valor contábil da amortização acumulada no início do período? \\
\hline & 11 & Divulgou o valor contábil da amortização do período? \\
\hline & 12 & Divulgou o valor contábil da amortização acumulada no final do período? \\
\hline & 13 & $\begin{array}{l}\text { Divulgou os métodos de amortização utilizados para ativos intangíveis } \\
\text { com vida útil definida? }\end{array}$ \\
\hline & 14 & $\begin{array}{l}\text { Divulgou a rubrica da demonstração de resultado em que qualquer } \\
\text { amortização de ativo intangível foi incluída? }\end{array}$ \\
\hline \multirow{5}{*}{$\begin{array}{l}\text { Adições/ } \\
\text { baixas }\end{array}$} & 15 & $\begin{array}{l}\text { Divulgou de forma separada o valor contábil das adições que foram } \\
\text { geradas por desenvolvimento interno e as adquiridas, bem como as } \\
\text { adquiridas por meio de uma combinação de negócios? }\end{array}$ \\
\hline & 16 & $\begin{array}{l}\text { Divulgou o valor justo inicialmente reconhecido dos ativos intangíveis } \\
\text { adquiridos por meio de subvenção ou assistência governamentais? }\end{array}$ \\
\hline & 17 & $\begin{array}{l}\text { Divulgou o valor contábil inicialmente reconhecido dos ativos intangíveis } \\
\text { adquiridos por meio de subvenção ou assistência governamentais? }\end{array}$ \\
\hline & 18 & $\begin{array}{l}\text { Divulgou se os ativos intangíveis adquiridos por meio de subvenção ou } \\
\text { assistência governamentais são mensurados, após o reconhecimento, } \\
\text { pelo método de custo ou reavaliação? }\end{array}$ \\
\hline & 19 & $\begin{array}{l}\text { Divulgou o valor contábil dos ativos classificados como mantidos para } \\
\text { venda ou incluídos em grupo de ativos classificados como mantidos para } \\
\text { venda e outras baixas? }\end{array}$ \\
\hline \multirow{3}{*}{$\begin{array}{l}\text { Reavaliação/ } \\
\text { Teste de } \\
\text { impairment }\end{array}$} & 20 & Divulgou a data efetiva da reavaliação do intangível? \\
\hline & 21 & $\begin{array}{l}\text { Divulgou o saldo da reavaliação, relacionada aos ativos intangíveis, } \\
\text { no início e no final do período? }\end{array}$ \\
\hline & 22 & $\begin{array}{l}\text { Divulgou informações sobre a realização ou não do teste de impairment, } \\
\text { de acordo com o Pronunciamento Técnico CPC } 01 \text { - Redução ao Valor } \\
\text { Recuperável de Ativos? }\end{array}$ \\
\hline
\end{tabular}

(continua) 
QUADRO 2 (CONCLUSÃO)

INFORMAÇÖES OBRIGATÓRIAS A SEREM

DIVULGADAS SOBRE ATIVO INTANGÍVEL

\begin{tabular}{ll}
\hline $\begin{array}{l}\text { DIMENSÃO } \\
\text { DE ATIVOS } \\
\text { INTANGIVEIS }\end{array}$ & PERGUNTAS PARA CONSTRUÇÃO DO ÍNDICE DE ATIVOS INTANGIVEIS \\
\hline $\begin{array}{l}\text { Reavaliação/ } \\
\text { Teste de } \\
\text { impairment }\end{array}$ & $\begin{array}{l}23 \\
\text { Divulgou o valor das provisões de perdas, reconhecidas no resultado do acordo com o Pronunciamento Técnico CPC } 01 \text { - Redução } \\
\text { ao Valor Recuperável de Ativos? }\end{array}$ \\
\cline { 2 - 2 } & $\begin{array}{l}\text { Divulgou o valor das reversões de perdas, reconhecidas no resultado do } \\
\text { período, de acordo com o Pronunciamento Técnico CPC 01 - Redução } \\
\text { ao Valor Recuperável de Ativos? }\end{array}$ \\
\hline
\end{tabular}

Fonte: Adaptado do CPC-04 (2008).

Para cada resposta poderiam ser atribuídas três notas (O, I ou 2), sendo nota o para aquelas que não estavam em conformidade com as determinações do CPC 04, nota I para as informações que foram apresentadas conforme as determinações do CPC 04 e nota 2 quando a questão não era aplicável para determinadas empresas. Por exemplo, na questão 7 , que pergunta se a empresa divulgou o valor contábil de ativos intangíveis cuja titularidade é restrita, alguma companhia da amostra pode não ter nenhum ativo intangível com titularidade restrita, portanto, a questão não é aplicável para ela. Nesse caso, a pontuação foi 2.

Se o índice fosse composto apenas por questões binárias (o e I), nesse exemplo mencionado, a empresa receberia pontuação o e poderia ser penalizada por não revelar um tipo específico de informação que não se aplica a sua realidade operacional. Ao final da coleta, as questões que receberam pontuação 2 (considerada não aplicável) foram removidas do índice, pois, caso não fossem, comprometeriam o resultado final. Dessa maneira, a pontuação compreende somente a soma das questões que receberam pontuação o e I.

No processo de coleta dos dados, planilhas do Microsoft Excel foram utilizadas para calcular o índice tamanho dos intangíveis e tabular as respostas dos índices de conformidade das informações divulgadas sobre ativos intangíveis e o índice de governança corporativa. Por fim, utilizou-se o teste de Kolmogorov-Smirnov para testar se a distribuição amostral de cada indicador possuía normalidade dos dados. O resultado do teste foi positivo para todas as variáveis. Dessa forma, optou-se por utilizar o coeficiente de correlação de Pearson. 


\section{DESCRIÇÃO E ANÁLISE DOS DADOS}

Esta seção contém a descrição e análise dos dados coletados. Primeiro, descreve-se a representatividade dos intangíveis nas empresas, caracterizada pelo percentual dos ativos intangíveis em relação ao ativo total no ano de 2009. Em seguida, as estatísticas descritivas do índice de conformidade das informações divulgadas sobre ativos intangíveis. Na sequência, as estatísticas descritivas do índice de governança corporativa e, por último, demonstram-se os resultados da correlação de Pearson que possibilitaram alcançar o objetivo do estudo.

Na Tabela 2, expõem-se os dados sobre a representatividade dos ativos intangíveis no ativo total das empresas, no ano de 2009 , dos setores econômicos da BM\&FBovespa.

\section{TABELA 2}

REPRESENTATIVIDADE DOS INTANGÍVEIS NO ATIVO TOTAL

DAS EMPRESAS NO ANO DE 2009 DE ACORDO COM OS SETORES ECONÔMICOS DA BM\&FBOVESPA

\begin{tabular}{lccccc}
\hline SETOR ECONÔMICO DA BM\&FBOVESPA & N EMPRESAS & $\begin{array}{c}\text { MÍNIMO } \\
(\%)\end{array}$ & $\begin{array}{c}\text { MÁXIMO } \\
(\%)\end{array}$ & $\begin{array}{c}\text { MÉDIA } \\
(\%)\end{array}$ & $\begin{array}{c}\text { DESVIO } \\
\text { PADRÃO (\%) }\end{array}$ \\
\hline Utilidade pública & 65 & 0,01 & 84 & 29 & 24 \\
\hline Construção e transporte & 67 & 0,01 & 98 & 23 & 32 \\
\hline Tecnologia da informação & 6 & 2,33 & 51 & 22 & 21 \\
\hline Consumo cíclico & 51 & 0,01 & 81 & 10 & 19 \\
\hline Bens industriais & 31 & 0,06 & 43 & 7 & 10 \\
\hline Materiais básicos & 40 & 0,02 & 56 & 6 & 12 \\
\hline Índice de intangibilidade & $\mathbf{2 6 0}$ & $\mathbf{0 , 0 1}$ & $\mathbf{9 8}$ & $\mathbf{1 7}$ & $\mathbf{2 4}$ \\
\hline
\end{tabular}

Fonte: Elaborada pelos autores.

O setor econômico de utilidade pública, que no ano de 2009 possuía 65 empresas com ativos intangíveis evidenciados no Balanço Patrimonial, destacou-se com o maior índice médio, ou seja, dentre o ativo total, as empresas desse setor possuíam, em média, o equivalente a $29 \%$ de ativos intangíveis. O índice mínimo desse setor (०,०1\%) foi obtido pela empresa Eletrobrás e o máximo, na empresa Cia de Saneamento Básico do Estado de São Paulo - Sabesp, em que os ativos intangíveis representavam $84 \%$ do ativo total. Portanto, ocorrem desigualdades nesse setor, conforme pode ser percebido pelo desvio padrão de $24 \%$. 
Os setores de construção e transporte e tecnologia da informação apresentaram índices médios semelhantes de $23 \%$ e $22 \%$, respectivamente. Porém, o setor de construção e transporte destacou-se por meio da empresa Concessionária Rota das Bandeirantes S.A., em que os ativos intangíveis representavam o maior percentual em relação ao ativo total da amostra, correspondente a $98 \%$.

Nos setores de bens industriais e materiais básicos constam as empresas com menores valores de intangíveis em relação ao ativo total, com índices médios de apenas $7 \%$ e $6 \%$. Além disso, as empresas desses setores apresentaram desvios padrão menores do que os demais setores, comprovando que a maioria das empresas desse setor realmente possuía menores proporções de ativos intangíveis em relação ao ativo total.

De maneira geral, os ativos intangíveis equivaliam a $17 \%$ do ativo total das 260 empresas analisadas. Esse percentual é superior ao encontrado por Ritta, Ensslin e Ronchi (20I0), que investigaram a representatividade dos intangíveis no ativo total de empresas que apresentaram informações financeiras à BM\&FBovespa e à NYSE nos anos de 2006 e 2007 , em que obtiveram um índice médio de representatividade equivalente a $12 \%$. No entanto, a diferença de resultados pode ser decorrente dos critérios de formação da amostra.

Na Tabela 3, são apresentados os resultados da avaliação das práticas de governança corporativa das empresas, por meio do índice de Leal e Carvalhal-da-Silva (2007).

\section{TABELA 3}

ÍNDICES DE GOVERNANÇA CORPORATIVA DO ANO

DE 2009 DE ACORDO COM OS SETORES DA BM\&FBOVESPA

\begin{tabular}{lccccc}
\hline SETOR ECONÔMICO DA BM\&FBOVESPA & $\begin{array}{c}N^{0} \\
\text { EMPRESAS }\end{array}$ & $\begin{array}{c}\text { MÍNIMO } \\
(\%)\end{array}$ & $\begin{array}{c}\text { MÁXIMO } \\
(\%)\end{array}$ & $\begin{array}{c}\text { MÉDIA } \\
(\%)\end{array}$ & $\begin{array}{c}\text { DESVIO } \\
\text { PADRÃO (\%) }\end{array}$ \\
\hline Utilidade pública & 65 & 33 & 83 & 57 & 11 \\
\hline Construção e transporte & 67 & 33 & 83 & 58 & 12 \\
\hline Tecnologia da informação & 6 & 50 & 83 & 71 & 12 \\
\hline Consumo cíclico & 51 & 31 & 79 & 52 & 13 \\
\hline Bens industriais & 31 & 28 & 83 & 50 & 11 \\
\hline Materiais básicos & $\mathbf{4 0}$ & 29 & 79 & 52 & 13 \\
\hline Índice de governança corporativa & $\mathbf{2 6 0}$ & $\mathbf{2 8}$ & $\mathbf{8 3}$ & $\mathbf{5 5}$ & $\mathbf{1 3}$ \\
\hline
\end{tabular}

Fonte: Elaborada pelos autores. 
Conforme a Tabela 3, a melhor média (71\%) de adoção das boas práticas de governança corporativa refere-se ao setor de tecnologia da informação. $\mathrm{O}$ índice mínimo do setor de tecnologia da informação foi de 50\%, obtido pela companhia Itautec, e o máximo foi de $83 \%$, conquistado pela companhia Totvs. O desvio padrão desse setor foi de apenas I2\%, demonstrando pouca variabilidade nos índices.

As empresas do setor de construção e transporte também se destacaram, pois, em média, tinham $58 \%$ das práticas de governança corporativa analisadas; o índice mínimo foi de 33\%, das companhias All América Malha Paulista e Trevisa Investimentos, e o máximo foi de $83 \%$, obtido pela companhia Santos Brasil Participações. O desvio padrão desse setor também foi baixo, demonstrando certa homogeneidade.

O setor de bens industriais apresenta a empresa com menor índice de governança corporativa da amostra, com apenas $28 \%$ das práticas consideradas necessárias por Leal e Carvalhal-da-Silva (2007). Esse índice foi obtido pela companhia Lark S.A.; o índice máximo do setor foi de 83\%, proveniente da empresa Kepler Weber S. A.

De forma geral, o índice médio de governança foi de $55 \%$, muito distante de I0०\%. A empresa com menor índice alcançou somente $28 \%$ de um total de 24 itens analisados, enquanto que o máximo atingido foi de $83 \%$. Ressalta-se o fato de que nenhuma empresa atingiu ı००\% de adesão às práticas de governança corporativa analisadas, e que os setores com maiores proporções de ativos intangíveis apresentaram índices médios mais elevados.

No entanto, ao comparar os resultados desta pesquisa com os de Lopes e Walker (2008), que investigaram a qualidade das práticas de governança corporativa das companhias abertas brasileiras nos anos de I998, 2000, 2002, 2004 e obtiveram um índice médio no período de $26 \%$, e com os de Silveira et al. (2010) no mesmo período pesquisado por Lopes e Walker (2008), que encontraram um índice médio de 4I,6\% (de um total de 24) em I998 e que evoluiu apenas para $50 \%$ (de um total de 24) em 2004, percebe-se que as empresas da amostra atual apresentaram melhores práticas de governança corporativa do que as empresas analisadas por Lopes e Walker (2008) e Silveira et al. (20I0) até $\mathrm{o}$ ano de 2004 .

A Tabela 4 apresenta as estatísticas descritivas do índice de conformidade das informações divulgadas sobre ativos intangíveis de cada setor econômico, conforme determinações do CPC 04, a fim de identificar se as empresas estão possibilitando que os usuários sejam capazes de compreender melhor os investimentos realizados em ativos intangíveis. 
TABELA 4

ESTATISTICA DESCRITIVA DO INDICE DE CONFORMIDADE DAS INFORMAÇÕES DIVULGADAS SOBRE ATIVOS INTANGÍVEIS NO ANO DE 2009 DE ACORDO COM OS SETORES ECONÔMICOS DA BM\&FBOVESPA

\begin{tabular}{lccccc}
\hline SETOR ECONÔMICO DA BM\&FBOVESA & No EMPRESAS & $\begin{array}{c}\text { MÍNIMO } \\
(\%)\end{array}$ & $\begin{array}{c}\text { MÁXIMO } \\
(\%)\end{array}$ & $\begin{array}{c}\text { MÉDIA } \\
(\%)\end{array}$ & $\begin{array}{c}\text { DESVIO } \\
\text { PADRÃO (\%) }\end{array}$ \\
\hline Utilidade pública & 65 & 21 & 100 & 69 & 21 \\
\hline Construção e transporte & 67 & 28 & 100 & 68 & 22 \\
\hline Tecnologia da informação & 6 & 71 & 100 & 90 & 10 \\
\hline Consumo cíclico & 51 & 28 & 100 & 65 & 20 \\
\hline Bens industriais & 31 & 29 & 85 & 63 & 17 \\
\hline Materiais básicos & 40 & 28 & 92 & 60 & 18 \\
\hline Índice de conformidade & $\mathbf{2 6 0}$ & $\mathbf{2 1}$ & $\mathbf{1 0 0}$ & $\mathbf{6 7}$ & $\mathbf{2 1}$ \\
\hline
\end{tabular}

Fonte: Elaborada pelos autores.

Observa-se na Tabela 4 que o setor econômico de tecnologia da informação se destacou, pois apresentou o maior índice médio de conformidade, equivalente a 90\%. O índice mínimo desse setor foi de $71 \%$, proveniente da companhia Itautec, e o máximo foi de I००\%, conquistado pelas companhias UOL e Ideiasnet, que evidenciaram todas as informações recomendadas pelo CPC 04. O desvio padrão desse setor foi de apenas ı०\%, o menor dentre os seis setores analisados, demonstrando que existem poucas diferenças entre os níveis de evidenciação nas empresas do setor.

As empresas do setor de utilidade pública também se destacaram, com um índice médio de $69 \%$. No entanto, nesse setor está a empresa com menor conformidade com o CPC 04, cumprindo apenas 21\% de suas determinações. Esse índice foi obtido pela empresa Cia. Energética de Brasília, que informou apenas a existência de ativos intangíveis e que eles têm a sua recuperabilidade testada anualmente. O índice máximo desse setor (ı००\%), com todas as informações evidenciadas, foi obtido pela empresa Uptick Participações S.A., mas o desvio padrão foi um pouco mais elevado do que o setor de tecnologia da informação.

Os setores de consumo cíclico, bens industriais e materiais básicos também apresentavam empresas com índices mínimos baixos de $28 \%$ e $29 \%$. Cabe 
ressaltar aqui que nenhuma empresa dos setores de bens industriais e materiais básicos divulgou I0०\% das informações recomendadas pelo CPC 04 .

De forma geral, os setores com maiores proporções de ativos intangíveis apresentaram índices de conformidade mais elevados - têm-se um índice médio de conformidade de $67 \%$, ainda bastante distante de $100 \%$. A empresa com menor índice alcançou $2 \mathrm{I} \%$ de um total de 24 itens analisados e o máximo (Iо०\%) foi atingido somente por II empresas das 260 que compõem a amostra de pesquisa.

Comparando esses resultados com os de Cunha et al. (2010), que analisaram o nível de evidenciação dos ativos intangíveis nos anos de 2005, 2007 e 2009, de acordo com a IAS 38 , em uma amostra de 40 empresas que negociavam ações na Bovespa, cujos resultados demonstraram que apenas sete empresas da amostra atingiram ı००\%, verifica-se que ainda há necessidade do aumento do nível de evidenciação obrigatória sobre os ativos intangíveis. Isso pode estar deixando de ocorrer em virtude de o CPC 04 ser recente, uma vez que foi aprovado e publicado em 2008.

A última etapa da pesquisa consistiu em verificar, empiricamente, se maiores proporções de ativos intangíveis no ativo total e melhores práticas de governança corporativa estão relacionadas com maior conformidade do CPC 04 entre empresas dos setores da BM\&FBovespa com maiores e menores representatividades de ativos intangíveis. Na Tabela 5, evidenciam-se os coeficientes de correlação de Pearson.

TABELA 5

CORRELAÇÃO DAS VARIÁVEIS DE ESTUDO

\begin{tabular}{lccc}
\hline ÍNDICES & $\begin{array}{c}\text { REPRES. DOS } \\
\text { INTANGIVEIS NO } \\
\text { ATIVO TOTAL }\end{array}$ & $\begin{array}{c}\text { ÍNDICE DE } \\
\text { GOVERNANÇA } \\
\text { CORPORATIVA }\end{array}$ & $\begin{array}{c}\text { CONFORMIDADE } \\
\text { COM O CPC 04 }\end{array}$ \\
\hline Repres. dos intangíveis no ativo total & 1 & - & - \\
\hline Índice de governança corporativa & $0,683^{* *}$ & 1 & 1 \\
\hline Conformidade com o CPC 04 & $0,582^{* *}$ & $0,707 * *$ & - \\
\hline
\end{tabular}

** Correlação estatisticamente significativa ao nível de significância de o,oI.

Fonte: Elaborada pelos autores.

Verifica-se, na Tabela 5, que a variável representatividade dos ativos intangíveis no ativo total tem uma correlação positiva de $68 \%$ com a variável índice de 
governança corporativa, estatisticamente significativa a um nível de o,o o. Confirmando as hipóteses expressas por Klappler e Love (2002) e Silveira (2002, 2004), que preconizam que empresas com maiores proporções de ativos intangíveis teriam maior necessidade de adotar melhores práticas de governança corporativa como forma de garantir aos diversos stakeholders que não farão mau uso dos seus intangíveis e, também, como forma de proporcionar maior segurança aos investidores.

Observa-se, ainda, que a variável representatividade dos ativos intangíveis tem uma correlação positiva de $58 \%$ com a variável índice de conformidade com o CPC o4, estatisticamente significativa a um nível de o,oı. Esse resultado apresentado se coaduna com o descrito na literatura (Himmelberg, Hubbard, \& Palia, I999; Klapper \& Love, 2004; Silveira, 2002, 2004; Antunes, Leite, \& Guerra, 2009) de que as empresas com maiores proporções de ativos intangíveis têm maior necessidade de evidenciar informações sobre eles, ou seja, divulgar mais informações para tornar-se mais transparentes e transmitir maior confiança ao mercado.

Quando se analisa a variável índice de governança corporativa em relação à variável conformidade das divulgações, percebe-se que também há correlação positiva de $70 \%$, estatisticamente significativa a um nível de significância de O,OI. Esse resultado confirma a descrição de Kent e Stewart (2008) e de Oliveira, Rodrigues e Craig (20I0), de que as boas práticas de governança corporativa contribuem para a adoção correta das normas internacionais de contabilidade e para o aumento da evidenciação de informações dos intangíveis.

Os achados para o ano de 2009 apontam para a confirmação de que maiores proporções de ativos intangíveis no ativo total e melhores práticas de governança corporativa estão relacionadas com maior conformidade do CPC o4 entre empresas dos setores da BM\&FBovespa com maiores e menores representatividades de ativos intangíveis.

\section{CONSIDERAÇÕES FINAIS}

O estudo objetivou verificar se empresas com maiores proporções de ativos intangíveis no ativo total e melhores práticas de governança corporativa apresentam maior conformidade com o disclosure obrigatório de tais ativos. Pesquisa descritiva, com abordagem quantitativa, foi conduzida por meio de análise documental, com consulta ao Balanço Patrimonial, Notas Explicativas, Relatórios de Administração e IANs disponíveis no site da BM\&FBovepa e websites das organizações. A amostra compreendeu 260 empresas de seis setores econômicos da 
BM\&FBovespa com maiores e menores representatividades de ativos intangíveis no ano de 2009 .

Em relação à representatividade dos intangíveis nos ativos totais das empresas, os resultados demonstraram existir representatividade dos intangíveis, que, de maneira geral, equivalem a I7\% do ativo total, com destaque para o setor econômico de utilidade pública, que obteve o maior índice médio de ativos intangíveis.

No que concerne à qualidade das práticas de governança corporativa, captadas por meio do índice proposto pelo estudo de Leal e Carvalhal-da-Silva (2007), encontrou-se um índice médio de governança de 55\%, muito distante de Io०\%. No entanto, ao comparar os resultados de 2009 com os de Lopes e Walker (2008) e com os de Silveira et al. (2010), percebeu-se que as empresas da amostra atual apresentaram melhores práticas de governança corporativa do que as empresas analisadas por esses autores até o ano de 2004. Ressalta-se que a diferença de resultados pode ser decorrente dos critérios de formação da amostra.

Os índices de governança corporativa demonstraram-se superiores nos setores de utilidade pública, construção e transporte e tecnologia da informação, que são aqueles com maiores proporções de intangíveis, com destaque para as empresas do setor de tecnologia da informação, com índice médio de 71\%.

Quanto à conformidade das informações divulgadas sobre ativos intangíveis, analisada por meio do índice de evidenciação baseado no CPC 04, os resultados revelaram um índice médio de conformidade de $75 \%$, bastante distante de I००\%. Os índices demonstraram-se superiores nos setores de utilidade pública, construção e transporte e tecnologia da informação, que são aqueles com maiores proporções de intangíveis. O setor econômico de tecnologia da informação destacou-se com o melhor índice médio de conformidade.

Por fim, os resultados do coeficiente de correlação de Pearson demonstraram: I. relação positiva e significativa estatisticamente de $68 \%$ entre representatividade dos ativos intangíveis e boas práticas de governança corporativa, 2. positiva e significativa de $58 \%$ entre representatividade e conformidade do disclosure obrigatório, 3. positiva e significativa de 70\% entre governança corporativa e conformidade do disclosure obrigatório.

Também foram realizados testes de correlação dessas variáveis: I. somente entre empresas dos setores com maiores representatividades de intangíveis, 2. somente entre as empresas dos setores com menores representatividades, 3. somente entre as empresas de cada um dos seis setores que compõem a pesquisa. De modo geral, os resultados mantiveram-se, em todos os testes, estatisticamente significantes e próximos a 68\%, 58\% e 70\%, como já descrito anteriormente.

Com base nos resultados da pesquisa, conclui-se que entre empresas de diferentes setores da BM\&FBovespa, aquelas com maiores proporções de ativos 
intangíveis no ativo total e melhores práticas de governança corporativa apresentaram maior conformidade com o disclosure obrigatório de tais ativos. Os resultados deste estudo despertam interesse em novas pesquisas sobre ativos intangíveis e governança corporativa. Assim, recomenda-se utilizar outros períodos de tempo, a fim de identificar tendências ou evoluções dos níveis de conformidade quanto à divulgação de informações sobre intangíveis ou sobre a qualidade das práticas de governança corporativa. Também seria interessante utilizar questionários ou realizar entrevistas para captar práticas de governança corporativa não divulgadas.

\section{CONFORMITY OF THE MANDATORY DISCLOSURE OF INTANGIBLE ASSETS AND CORPORATE GOVERNANCE PRACTICES}

\section{ABSTRACT}

The goal of this study is to verify whether the companies with higher proportions of intangible assets in total assets and best practices of corporate governance have higher conformity with the mandatory disclosure of such assets. A descriptive research, with quantitative approach, was conducted through document analysis in a sample of 260 companies in six economic sectors of BM\&FBovespa. For each company it was calculated the percentage of intangible assets compared to the total assets, the corporate governance index based on the study of Leal and Carvalhal-da-Silva (2007) and the conformity rate of the information disclosed about intangible assets. The results revealed representation of intangibles, generally equivalent to $17 \%$ of total assets, but some companies, especially those in sectors with higher proportions, have more significant rates. In quality of governance practices was identified an average rate of $55 \%$ and the level of information disclosure on intangibles an average rate of $75 \%$. Pearson's correlation was positive and statistically significant, corroborating the description in the study purpose. It is concluded that among companies in different sectors of BM\&FBovespa, those with higher proportions of intangible assets in total assets and best practices in corporate governance have higher conformity with the mandatory disclosure of such assets.

\section{KEYWORDS}

Mandatory disclosure. Intangible assets. Total assets. Best practices. Corporate governance. 


\section{CONFORMIDAD DE LA DECLARACIÓN OBLIGATORIA DE LOS ACTIVOS INTANGIBLES Y PRÁCTICAS DE GOBIERNO CORPORATIVO}

\section{RESUMEN}

El estudio tiene como objetivo verificar si las empresas con mayor proporción de los activos intangibles en activos totales y las mejores prácticas de gobierno corporativo tienen una mayor conformidad con la divulgación obligatoria de dichos activos. Un estudio descriptivo, con enfoque cuantitativo, se llevó a cabo a través del análisis de documentos en una muestra de 260 empresas en seis sectores económicos de la BM\&FBovespa. Para cada empresa se calculó el porcentaje de los activos intangibles en comparación a los activos totales, el índice de gobierno corporativo basado en el estudio de Leal y Carvalhal-da-Silva (2007) y el porcentaje de conformidad de la información divulgada sobre los activos intangibles. Los resultados revelaron la representación de los intangibles, generalmente equivalente al $17 \%$ del total de activos, pero algunas empresas, especialmente aquellas en los sectores con mayor proporción, tienen tasas más significativas. En calidad de las prácticas de gobierno se identificó una tasa promedio del $55 \%$ y el nivel de divulgación de información sobre intangibles una tasa promedio del $75 \%$. La correlación de Pearson fue positivo y estadísticamente significativo, lo que corrobora el objetivo descrito en el estudio. Por lo tanto, llegamos a la conclusión de que entre las empresas de diferentes sectores de la BM\&FBovespa, los que tienen una mayor proporción de los activos intangibles en activos totales y las mejores prácticas de gobierno corporativo tienen una mayor conformidad con la divulgación obligatoria de dichos activos.

\section{PALABRAS CLAVE}

Divulgación requerida. Activos intangibles. Total de activos. Mejores prácticas. Gobierno corporativo.

\section{REFERÊNCIAS}

Aksu, M., \& Kosedag, A. (2006). Transparency and disclosure scores and their determinants in the Istanbul stock exchange. Corporate Governance, 14(4), 277-296.

Andrade, A., \& Rossetti, J. P. (2007). Governança corporativa: fundamentos, desenvolvimento e tendências. (3a ed.). São Paulo: Atlas. 
Antunes, M. T. P. (2004). A influência dos investimentos em capital intelectual no desempenho das empresas: um estudo baseado no entendimento de gestores de grandes empresas brasileiras. Tese de Doutorado, Universidade de São Paulo, São Paulo, SP, Brasil.

Antunes, M. T. P., Leite, R. S., \& Guerra, L. F. (2009, setembro). Divulgação das informações sobre ativos intangíveis e sua utilidade para avaliação de investimentos: um estudo exploratório baseado na percepção dos analistas de investimentos. Anais do Congresso USP de Controladoria e Contabilidade, São Paulo, SP, Brasil, 9.

Antunes, M. T. P., Silva, L. C. P., \& Saiki, T. G. (2009, novembro). Evidenciação dos ativos intangíveis (capital intelectual) por empresas brasileiras à luz da Lei n. Iı.638/07. Anais do Congresso Brasileiro de Custos, Fortaleza, CE, Brasil, I6.

Backes, R. G., Ott, E., \& Wiethaeuper, D. (2005, julho). Informações sobre capital intelectual evidenciadas pelas companhias abertas listadas em Nível I de governança corporativa da Bovespa. Anais do Congresso USP de Controladoria e Contabilidade, São Paulo, SP, Brasil, 5.

Bebchuk, L. A., \& Weisbach, M. S. (2010). The state of corporate governance research. The Review of Financial Studies, 23(3), 325-346.

Beekes, W., \& Brown, P. (2006). Do Better-Governed Australian firms make more informative disclosures? Journal of Business Finance \& Accounting, 33(4), 422-450.

Black, B. (200I). The corporate governance behavior and market value of Russian firms. Emerging Markets Review, 2(2), 89-108.

Black, B. S., Jang, H., \& Kim, W. (2006). Does corporate governance predict firms' market values? Evidence from Korea. The Journal of Law, Economics, \& Organization, 22(2), 366-4I3.

Brooking, A. (1996). Intellectual capital: core asset for the third millennium enterprise. Boston: Thomson Publishing Inc.

Caddy, I. (2002). Issues concerning intellectual capital metrics and measurement of intellectual capital. Singapore Management Review, 24(3), 77-88.

Carvalho, A. G. (2002). Governança corporativa no Brasil em perspectiva. Rausp. Revista de Administração da USP, 37(3), I9-32.

Comissão de Valores Mobiliários (CVM). Deliberação CVM n. 488/05. Recuperado em 20 setembro, 20Iо, de www.cpc.org.br.

Comissão de Valores Mobiliários (CVM). Deliberação CVM n. 553/o8. Recuperado em 20 setembro, 20Iо, de www.cpc.org.br.

Comitê de Pronunciamentos Contábeis (CPC). (2008). Pronunciamento Conceitual Básico. Recuperado em 20 setembro, 20I0, de www.cpc.org.br.

Comitê de Pronunciamentos Contábeis (CPC). (2008). Pronunciamento Técnico CPC 04 - Ativos Intangíveis. Recuperado em 20 setembro, 2010, de www.cpc.org.br.

Crawford, R. (I994). Na era do capital humano. São Paulo: Atlas.

Crisóstomo, V. L., \& Freire, F. S. (2005, novembro). Considerações sobre os ativos intangíveis no Brasil. Anais do Congresso Internacional de Custos, Itapema, SC, Brasil, 9.

Cunha, A. G., Souza, A. A., Santana, L. F., Magalhães, V. G., Pelegrini, V. S. P., \& Malaquias, R. F. (20I0, agosto). Evidenciação de ativos intangíveis: um estudo com empresas brasileiras. Anais do Simpósio de Excelência em Gestão e Tecnologia, Rio de Janeiro, RJ, Brasil, 7.

Decker, F., Ensslin, S. R., Reina, D. R. M., \& Reina, D. (2013). A relação entre os ativos intangíveis e a rentabilidade das ações: um estudo com empresas listadas no índice Bovespa. Reuna, 18(4), 75-92. 
Edvinsson, L., \& Malone, M. S. (1998). Capital intelectual: descobrindo o valor real de sua empresa pela identificação de seus valores internos. São Paulo: Makron Books.

Financial Accounting Standard Board (Fasb). (200I). Statement of Financial Accounting Standards 142 - Goodwill and Other Intangible Assets. Norwalk, CT: Fasb.

Galo, T. (2009). Estudo sobre a identificação, mensuração e evidenciação dos ativos intangíveis em empresa de commodities agrícolas no Brasil. Dissertação de Mestrado, Universidade Presbiteriana Mackenzie, São Paulo, SP, Brasil.

Goldfinger, C. (I997). Intangible economy and its implications for statistics and statisticians. International Statistical Review, 65(2), I9I-220.

Gompers, P., Ishii, J., \& Metrick, A. (2003). Corporate governance and equity prices. Quarterly Journal of Economics, 118(I), I07-I55.

Healy, P. M., \& Palepu, K. G. (200I). Information asymmetry, corporate disclosure, and the capital markets: a review of the empirical disclosure literature. Journal of Accounting and Economics, 31(I/3), 405-440.

Hendriksen, E. S., \& Van Breda, M. F. (I999). Teoria da contabilidade. São Paulo: Atlas.

Himmelberg, C., Hubbard, G., \& Palia, D. (I999). Understanding the determinants of managerial ownership and the link between ownership and performance. Journal of Financial Economics, 53(3), 353-384.

Hitt, M. A., Ireland, R. D., \& Hoskisson, R. E. (2003). Administração estratégica: competitividade e globalização (4a ed.). São Paulo: Thomson.

International Accounting Standards Board (Iasb). (2004). IAS 38 - Intangible Assets. London: International Accounting Standards Board.

Instituto Brasileiro de Governança Corporativa (IBGC). (2009). Código das Melhores Práticas de Governança Corporativa (4a ed.). Instituto Brasileiro de Governança Corporativa. São Paulo: IBGC. Iudícibus, S. (2004). Teoria da contabilidade (8a ed.). São Paulo: Atlas.

Johanson, U., Martensson, M., \& Skoog, M. (200I). Mobilizing change through the management control of intangibles. Accounting, Organizations and Society, 26(7/8), 715-733.

Jordão, R. V., \& Colauto, R. D. (2009, outubro). Governança corporativa e evidenciação voluntária de ativos intangíveis: um estudo nos setores de telecomunicações e de utilidade pública. Anais de Seminários em Administração, São Paulo, SP, Brasil, II.

Kaufmann, L., \& Schneider, Y. (2004). Intangibles: a synthesis of current research. Journal of Intellectual Capital, 5(3), 366-388.

Kayo, E. K. (2002). A estrutura de capital e o risco das empresas tangível e intangível-intensivas. Tese de Doutorado, Universidade de São Paulo, São Paulo, SP, Brasil.

Kayo, E. K., Teh, C. C., \& Basso, L. F. C. (2006). Ativos intangíveis e estrutura de capital: a influência das marcas e patentes sobre o endividamento. Rausp. Revista de Administração da USP, 41(2), I58-I68.

Keenan, J., \& Aggestam, M. (200I). Corporate governance and intellectual capital: some conceptualisations. Journal Corporate Governance, 9(4), 259-275.

Kent, P., \& Stewart, J. (2008). Corporate governance and disclosures on the transition to International. Journal Accounting \& Finance, 48(4), 649-67I.

Khanchel, I. (2007). Corporate governance: measurement and determinant analysisl. Managerial Auditing Journal, 22(8), 740-760. 
Klapper, L., \& Love, I. (2004). Corporate governance, investor protection, and performance in emerging markets. Journal of corporate Finance, 10(5), 703-728.

Lanzana, A. P. (2004). Relação entre disclosure e governança corporativa das empresas brasileiras. Dissertação de Mestrado, Universidade de São Paulo, São Paulo, SP, Brasil.

Leal, R. P. C., \& Carvalhal-da-Silva, A. L. (2007). Corporate governance and value in Brazil (and in Chile). In A. Chong, \& F. Lopes-De-Silanes. (Org.). Investor protection and corporate governance: firm level evidence across Latin America. (pp. 213-287). Palo Alto: Stanford University Press.

Lei n. 11.638, de 28 de dezembro de 2007 . Altera e revoga dispositivos da Lei n. 6.404, de I5 de dezembro de 1976 , e da Lei n. 6.385, de 7 de dezembro de 1976 , e estende às sociedades de grande porte disposições relativas à elaboração e divulgação de demonstrações financeiras. Diário Oficial da União. Brasília, DF: República Federativa do Brasil.

Lev, B. (200I). Intangibles: management, measurement, and reporting. Washington: Brookings.

Lopes, A. B., \& Martins, E. (2007). Teoria da contabilidade: uma nova abordagem (2a ed.). São Paulo: Atlas.

Lopes, A. B., \& Walker, M. (2008). Firm-lavel inventives and the informativeness of accounting reports: an expreriment in Brazil. Working Paper, 2008. Recuperado em 20 novembro, 20I0, de http://papers.ssrn.com.

Macagnan, C. B. (2009). Evidenciação voluntária: fatores explicativos da extensão da informação sobre recursos intangíveis. Revista Contabilidade \& Finanças, 20(50), 46-6I.

Marconi, M. A., \& Lakatos, E. M. (2002). Técnicas de pesquisa: planejamento e execução de pesquisas, amostragens e técnicas de pesquisas, elaboração, análise e interpretação de dados (5a ed.). São Paulo: Atlas. Martins, E. (I972). Contribuição à avaliação do ativo intangivel. Tese de Doutorado, Universidade de São Paulo, São Paulo, SP, Brasil.

Martins, E. (2002). Capital intelectual: verdades e mitos. Revista Contabilidade \& Finanças, 13(29), 4I-54.

Martins, G. A., \& Theóphilo, C. R. (2007). Metodologia da investigação científica para ciências sociais aplicadas. São Paulo: Atlas.

Matos, B., Ensslin, S. R., Reina, D., \& Reina, D. R. M. (2009, julho). A evidenciação voluntária do capital intelectual de natureza social e ambiental da empresa Natura Cosméticos S.A. no período de 2003 a 2007. Anais do Congresso USP de Contabilidade e Controladoria, São Paulo, SP, Brasil, 9. Milone, M. C. M. (2004). Cálculo do valor de ativos intangíveis: uma metodologia alternativa para a mensuração do valor de marcas. Tese de Doutorado, Universidade de São Paulo, São Paulo, SP, Brasil. Moura, G. D., Mecking, D. V., \& Scarpin, J. E. (2013). Competitividade de mercado, ativos intangíveis e eficiência na combinação dos ativos fixos em companhias abertas listadas na BM\&FBovespa. Enfoque: Reflexão Contábil, 32(3), I9-35.

Nascimento, A. M., \& Reginato, L. (2008). Divulgação da informação contábil, governança corporativa e controle organizacional: uma relação necessária. Revista Universo Contábil, 4(3), 25-47.

Nascimento, E. M., Oliveira, M. C., Marques, V. A., \& Cunha, J. V. A. (2012). Ativos intangíveis: análise do impacto do grau de intangibilidade nos indicadores de desempenho empresarial. Enfoque: Reflexão Contábil, 31(I), 37-52.

Oliveira, L., Rodrigues, L. L., \& Craig, R. (20I0). Intangible assets and value relevance: evidence from the Portuguese stock exchange. The British Accounting Review, 42(4), 24I-262. 
Pereira, C. A., Lemes, S., Alves, D. L., \& Ferreira, H. C. (2007, outubro). Mensuração e o reconhecimento dos ativos intangíveis de acordo com normas brasileiras e americanas. Anais de Seminários em Administração, São Paulo, SP, Brasil, ıo.

Perez, M. M., \& Famá, R. (2006). Ativos intangíveis e o desempenho empresarial. Revista Contabilidade \& Finanças, 17(40), 7-24.

Prado, K. S. (20I0). A aplicabilidade das práticas de governança corporativa nas sociedades limitadas. Dissertação de Mestrado, Pontifícia Universidade Católica de São Paulo, São Paulo, SP, Brasil.

Rêgo, T. F., Araújo Neto, P. L., Barbosa, E. S., \& Cavalcante, P. R. N. (2008). Evidenciação do capital intelectual nas empresas do segmento de papel e celulose, registradas na Bovespa. Anais do Congresso Brasileiro de Custos, Curitiba, PR, Brasil, I5.

Rezende, A. J., Facure, C. E. F., \& Dalmácio, F. Z. (2009, julho). Práticas de governança corporativa em organizações sem fins lucrativos. Anais do Congresso USP de Controladoria e Contabilidade, São Paulo, SP, Brasil, 9.

Richardson, R. J. (I999). Pesquisa social: métodos e técnicas (3a ed.). São Paulo: Atlas.

Ritta, C. O., Ensslin, S. R., \& Ronchi, S. H. (20ı0). A evidenciação dos ativos intangíveis nas empresas brasileiras: empresas que apresentaram informações financeiras à Bolsa de Valores de São Paulo e Nova York em 2006 e 2007. Revista Eletrônica de Ciência Administrativa, 9(I), 62-75.

Rolim, M. V. (2009). Estudo do nível de disclosure dos ativos intangíveis das empresas britânicas pertencentes ao indice FTSE 100. Dissertação de Mestrado, Universidade Federal de Uberlândia, Uberlândia, MG, Brasil.

Santos, A. P. G., Gallon, A. V., \& Ensslin, S. R. E. (2007, novembro). Um estudo descritivo da evidenciação do capital intelectual nas maiores companhias abertas da região Sul do Brasil. Anais do Congresso Brasileiro de Custos, João Pessoa, PB, Brasil, I4.

Schmidt, P., \& Santos, J. L. (2002). Avaliação de ativos intangíveis. São Paulo: Atlas.

Schnorrenberger, D. (2005). Identificando, avaliando e gerenciando recursos organizacionais tangiveis e intangíveis por meio de uma metodologia construtivista (MCDA): uma ilustração na área econômico-financeira. Tese de Doutorado, Universidade Federal de Santa Catarina, Florianópolis, SC, Brasil. Schnorrenberger, D., Sousa, B. J., \& Reina, D. (2009, novembro). Estudo sobre a evidenciação de capital intelectual das maiores distribuidoras de energia elétrica do Brasil. Anais do Congresso Brasileiro de Custos, Fortaleza, CE, Brasil, I6.

Silveira, A. D. M. (2002). Governança corporativa, desempenho e valor da empresa no Brasil. Dissertação de Mestrado, Universidade de São Paulo, São Paulo, SP, Brasil.

Silveira, A. D. M. (2004). Governança corporativa e estrutura de propriedade: determinantes e relação com o desempenho das empresas no Brasil. Tese de Doutorado, Universidade de São Paulo, São Paulo, SP, Brasil.

Silveira, A. D. M., Leal, R. P. C., Barros, L. A. B. C., \& Carvalhal-da-Silva, A. L. (2009). Evolution and determinants of firm-level corporate governance quality in Brazil. Rausp. Revista de Administração da Universidade de São Paulo, 44(3), I73-189.

Silveira, A. D. M., Leal, R. P. C., Carvalhal-da-Silva, A. L., \& Barros, L. A. B. C. (20I0). Endogeneity of Brazilian corporate governance quality determinants. Journal of Corporate Governance, 10(2), I9I-202.

Sriram, R. S. (2008). Relevance of intangible assets to evaluate financial health. Journal of Intellectual Capital, 9(3), 351-366. 
Stewart, T. A. (I998). Capital intelectual: a nova vantagem competitiva das empresas. Rio de Janeiro: Campus.

Sveiby, K. E. (1998). A nova riqueza das organizações: gerenciando e avaliando patrimônios de conhecimento. Rio de Janeiro: Campus.

Tavares, M. F. N. (20IO). Reconhecimento, mensuração e evidenciação contábil: um estudo sobre o nível de conformidade das empresas listadas na Bovespa com o CPC 01 - redução ao valor recuperável de ativos. Dissertação de Mestrado, Universidade Federal de Pernambuco, Recife, PE, Brasil.

Vargas, V. C. C. (2007). Medida padronizada para avaliação de intangíveis organizacionais por meio da teoria da resposta a item. Tese de Doutorado, Universidade Federal de Santa Catarina, Florianópolis, SC, Brasil.

Vergara, S. C. (2000). Projetos e relatórios de pesquisa em administração (3a ed.). São Paulo: Atlas. 